\title{
Experimental Investigation of the Impact of Compression on the Petro-Physical and Micromechanical Properties of Wellbore Cement Containing Salt
}

\author{
Arome Oyibo, Mileva Radonjic \\ Craft \& Hawkins Department of Petroleum Engineering, Louisiana State University, Baton Rouge, \\ LA, USA \\ Email: aromeoyibo@gmail.com, mileva@lsu.edu
}

Received 24 November 2015; accepted 28 June 2016; published 1 July 2016

Copyright (C) 2016 by authors and Scientific Research Publishing Inc.

This work is licensed under the Creative Commons Attribution International License (CC BY). http://creativecommons.org/licenses/by/4.0/

(c) (i) Open Access

\begin{abstract}
In this study, we investigated the effect of compression on the micromechanical and the petrophysical properties of salted wellbore cement systems. The experiments were conducted using a customized bench scale model, which utilized an expandable tubulars simulating the compression of a previously cemented casing under field-like conditions. The "mini-wellbore model" sample consisted of a pipe inside pipe assembly with a cemented annulus. The cement samples were cured in a water bath for $\mathbf{2 8}$ days prior to the compression experiments to allow adequate hydration. The impact of compression on the cement's petro-physical and mechanical properties was quantified by measuring the porosity, permeability and hardness of salt cement cores drilled parallel to the orientation of the pipe from the compacted cement sheath. Permeability (Core-flood) experiments were conducted at $21^{\circ} \mathrm{C}, 10,342 \mathrm{kPa}$ confining pressure for a period of 120 minutes. During the core-flood experiments, conducted using Pulse-decay method, deionized water was flowed through cement cores to determine the permeability of the cores. The results obtained from these experiments confirmed that the compression of the cement positively impacted the cements ability to provide long term zonal isolation, shown by the effective reduction in porosity and permeability. Furthermore, the results confirm reduction in the detrimental effect of salt on the strength and stiffness in post-compression cement.
\end{abstract}

\section{Keywords}

Zonal Isolation, Wellbore Leakage, Well Integrity, Salt Cement, Compression, Wellbore Cement as an Engineered Hydraulic Barrier 


\section{Introduction}

Wellbore cementing which forms an integral part of well completion is important in ensuring effective zonal isolation of the well. In addition to providing zonal isolation, oil well cements are also used to protect the casing from corrosive fluids that often have low $\mathrm{pH}$ such as $\mathrm{CO}_{2}$ and $\mathrm{SO}_{4}$ and to provide mechanical support for the casing. Cement behaves differently depending on the properties of the components/additives used in the design of the cement slurry [1]. The advances in shale exploration for oil and gas using hydraulic fracturing techniques and ultra-deep drilling through salt formations mostly in the US Gulf of Mexico have created an energy boom in the USA [2]: Several drilling and cementing challenges are associated with drilling through and cementing across such formations especially salt-containing formations [3]. In order to overcome these challenges, salted cement systems are employed in cementing through such zones. Salt cement systems have proven effective in the maintenance of formation competency in shale sections and salt cement blends have also been used in the field to minimize the inflow of gas into primary cement slurry column of wells in the ten section of Kern County field with severe damaging effect on the cement integrity [4]. Salt is mainly, added to the cement slurry to achieve better compatibility with salt formation and offset bulk hydration shrinkage [5]. High concentration of salt (over 18\% By Weight of Water, BWOW) is very effective dispersants or thinners and this helps in lowering the yield point and gel strength of the cement slurry [6]. The effect of salt on degradation of cement mortar, compressive strength and concrete corrosion has been extensively reviewed and documented in Civil and Environmental Fields [7] [8]. Salt however, has also been shown to have some damaging effects on oil-well cements. As a mild acid, salt lowers the $\mathrm{pH}$ of cement and attracts more water into the pore structure of the cement, leaving room for precipitation of new minerals and changing phases leading to fracture initiation and propagation [5]. Considerable work has been done over time on the applicability of salt cement blends with focus on improved cement-formation bonding and experience has shown that cement-formation bond through salt zones can only be achieved by using salt cement systems [9]. The mechanical properties of cement such as hardness and compressive strength have been shown to be significantly affected by the amount of water present in a hydrated cement paste. The Vickers hardness and the water to cement ratio have been found to be linearly related for different cement samples using the micro-indentation technique in the determination of the hardness of cement [10]. Review of current literature has revealed no documented findings on the effects of oil-field operations such as hydraulic fracturing and pressure variations during casing testing and geological impacts such as formation subsidence, which results in the compression of the cement on the micro-mechanical and petro-physical properties of the cement.

In this paper, we present our findings from an experimental determination of the impact of compression during hydraulic fracturing and the effect of pressure variation during pressure testing and hydrocarbon production on the petro physical and micro-mechanical properties of salted cement systems placed in the subsurface as an integral part of oil well construction.

\section{Experimental Methodology}

The experimental approach adopted for this study involves the use of a bench scale expansion fixture with customized expansion cones for expanding metal pipe, and compressing cement simulating expansion methodology performed in the field [11]. The wellbore model consists of a pipe inside pipe assembly with a cemented annulus, $60.96 \mathrm{~cm}$ length. An expansion cone with diameter larger than the inner diameter of the pipe is forced through the inner pipe thereby expanding the pipe and the pipe in turn compresses the cement sheath behind it towards the outer pipe (in real world that would be rock) [12]. The pipe component assembly was cut into discs of 7.62 $\mathrm{cm}$. long and cement cores were drilled from the cement sheath between the inner and outer pipe before (from control samples) and after different levels of expansion. The drilled cores were used for porosity and permeability measurements. The porosities of the cement cores were measured using a Grain Volume Device (Helium Porosimeter), Model UPore-300, Core Laboratories, Tulsa, Oklahoma, USA. The permeability's of the cement cores were measured using the Liquid Pressure Pulse Decay Permeameter, Geothermal System, Model CFS-200, Core Laboratories, Tulsa, Oklahoma, USA. The hardness of the cement cores was measured using the Nanovea Micro-Hardness Tester based on the standards for instrumented indentation, ASTM E3546 and ISO 14577 [13].

\section{Materials and Methods}

The main tool used for the tubular expansion in this experimental study is the expansion fixture. The expansion 
fixture, which is a physical model used to replicate the field operation performed during casing expansion consists of a 133,447 $\mathrm{N}$ hydraulic expansion system. The system is divided into six main parts; the hydraulic power unit, the hydraulic cylinder, expansion and retaining mandrel, the upper and lower housing units, a control switch, and an integrated load cell. The details and working principle of the expansion fixture have been documented in an earlier publication [11].

\subsection{Expansion Cones}

Three sets of expansion cones were used in this study: $2 \%, 4 \%$ and $8 \%$ expansion ratio cones. Each of the three expansion cones used have a cone angle of $14^{\circ}$ and made from AISI D2 grade alloy. The expansion cones are usually placed in the sample to be expanded through the lower end of the expansion mandrel and then held in place with the retaining mandrel to secure the cone within the sample under expansion. The impact of the expansion rate on the cement is dependent on several factors such as thickness of cement sheath; pipe wall thickness smoothness of the inner section of the pipe etc. However, previous studies [11] [14] have shown that the impact of compression on the cement sheath increases with increasing expansion ratio.

\subsection{Cement Slurry Design}

The $16.4 \mathrm{lb}$./gal with $10 \%$ salt $(\mathrm{NaCl})$ concentration by weight of water (BWOW) cement slurry used in the study was prepared in accordance with American Petroleum Institute-Recommended Practice 10B (API-RP10B) for testing Oil-well Cements. $2868 \mathrm{~g}$ of class $\mathrm{H}$ cement was mixed with $1090 \mathrm{~g}$ of deionized water in a blender at 20,800 revolutions per minute for 45 seconds resulting in a $1.97 \mathrm{~g} / \mathrm{cm}^{3}$ cement slurry with a water-cement ratio of 0.38 [15] [16]. Lafarge Class $\mathrm{H}$ cement was used in preparation of all the cement samples and all the samples were prepared and cured in a water bath at ambient conditions for a minimum of 28 days. The composite samples were covered with wet cloth and left to set and harden for 24 hours before being placed in a water bath for further hydration. The cement slurry was carefully poured into the annular space between the outer and inner pipe of the pipe inside pipe assembly and cure for 28 days in a water bath containing $\mathrm{Ca}(\mathrm{OH})_{2}$ to maintain the $\mathrm{pH}$ of the water at approximately 13.

\subsection{Pipe Component Design}

Two sets of pipes were used in the design of the wellbore model (Figure 1), a 12.7-cm nominal diameter carbon steel pipe (outer diameter of $14.1 \mathrm{~cm}$ and wall thickness of $1.45-\mathrm{cm}$ ) ASTM A53 grade B electrically resisted welded (ERW) and a $5.08 \mathrm{~cm}$. nominal diameter carbon steel pipe (outer diameter of $6 \mathrm{~cm}$ and wall thickness of $0.28 \mathrm{~cm}$. The pipes were cut into $60.96 \mathrm{~cm}$ long sections to fit into the experimental fixture. The yield strength and tensile strength rating of the pipes are $241,317 \mathrm{kPa}$ and 413,685 $\mathrm{kPa}$ respectively. The $5.08 \mathrm{~cm}$ nominal diameter pipe was made by founding steel plates into a tubular shape and then welded together. The pipes were properly cleaned and coated with zinc anti-corrosive spray as well as metallic Rust-Oleum metal finish after assembly to prevent corrosion during the period of hydration. 32 holes in total, with four holes, $90^{\circ}$ apart circumferentially and $5.08 \mathrm{~cm}$ apart longitudinally were drilled on the outer pipe to achieve two main objectives; First, to create a pathway for excess water and pressure relief during the expansion process and secondly as outlet and inlet ports for the flow through experiments. $0.396 \mathrm{~cm}$ and $0.874 \mathrm{~cm}$ drill bits were used in drilling the large and the small holes on the outer pipes respectively.

\subsection{Drilling of Cement Cores}

The pipe component assembly was cut into discs of $7.62 \mathrm{~cm}$ long (Figure 2) and $2.54 \times 5.08 \mathrm{~cm}$ cement cores were drilled from the cement sheath between the inner and outer pipe before and after expansion. The cores were drilled using a customized $2.54 \times 7.62 \mathrm{~cm}$ drill bit under a carefully controlled environment to be used for porosity and permeability measurements.

\subsection{Micro Indentation}

The Micro-indentation tests were performed using an established method where an indenter with a known geometry is driven into a specific site of the sample by the application of an increasing normal load. The Nanovea 


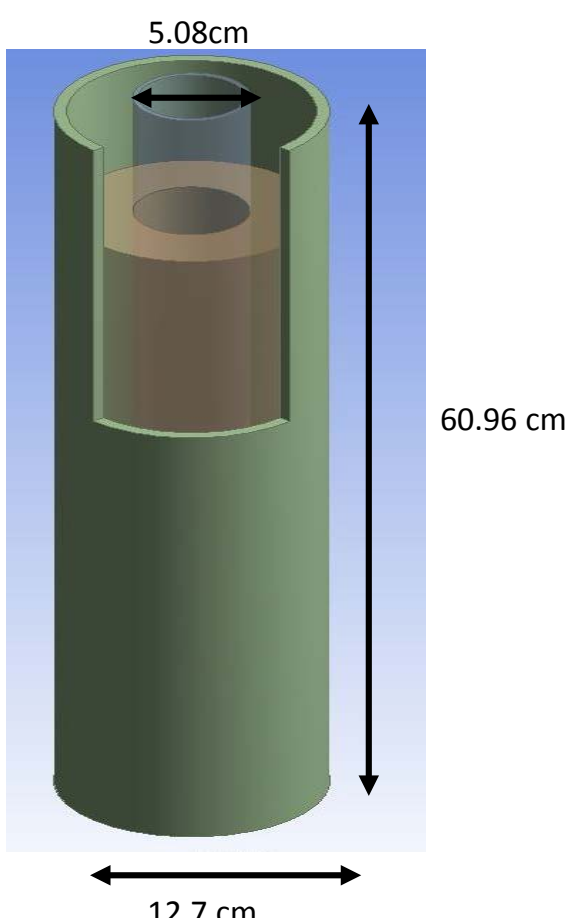

Figure 1. Schematic of the composite samples (wellbore model) showing the dimensions of the inner and outer pipes used in the composite design.

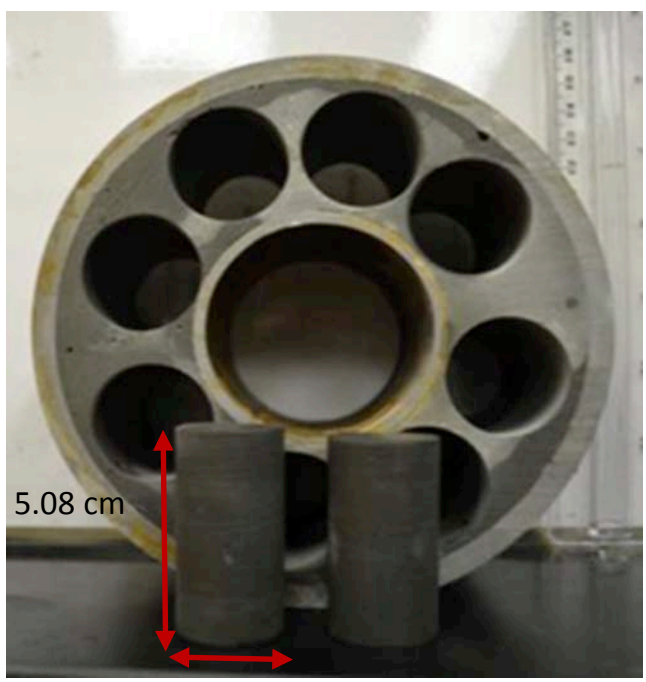

Figure 2. Image of the composite pipe-cement assembly showing the drilled cores.

Micro Hardness Tester (Figure 3) was used in this study following the standards for instrumented indentation ASTM E2546 and ISO 14577 [13].

The indenter moves with the aid of a magnet and coil assembly and the displacement of the indenter in the vertical direction is measured using a capacitance displacement gauge while the motorized stage is used to position the sample below the indenter tip. The point of indentation is selected with the help of an optical microscope attached to the equipment. The Vickers Diamond indenter was driven into the sample under test by applying an increasing normal load to the top of the sample until it reaches a preset value. The normal load is then 


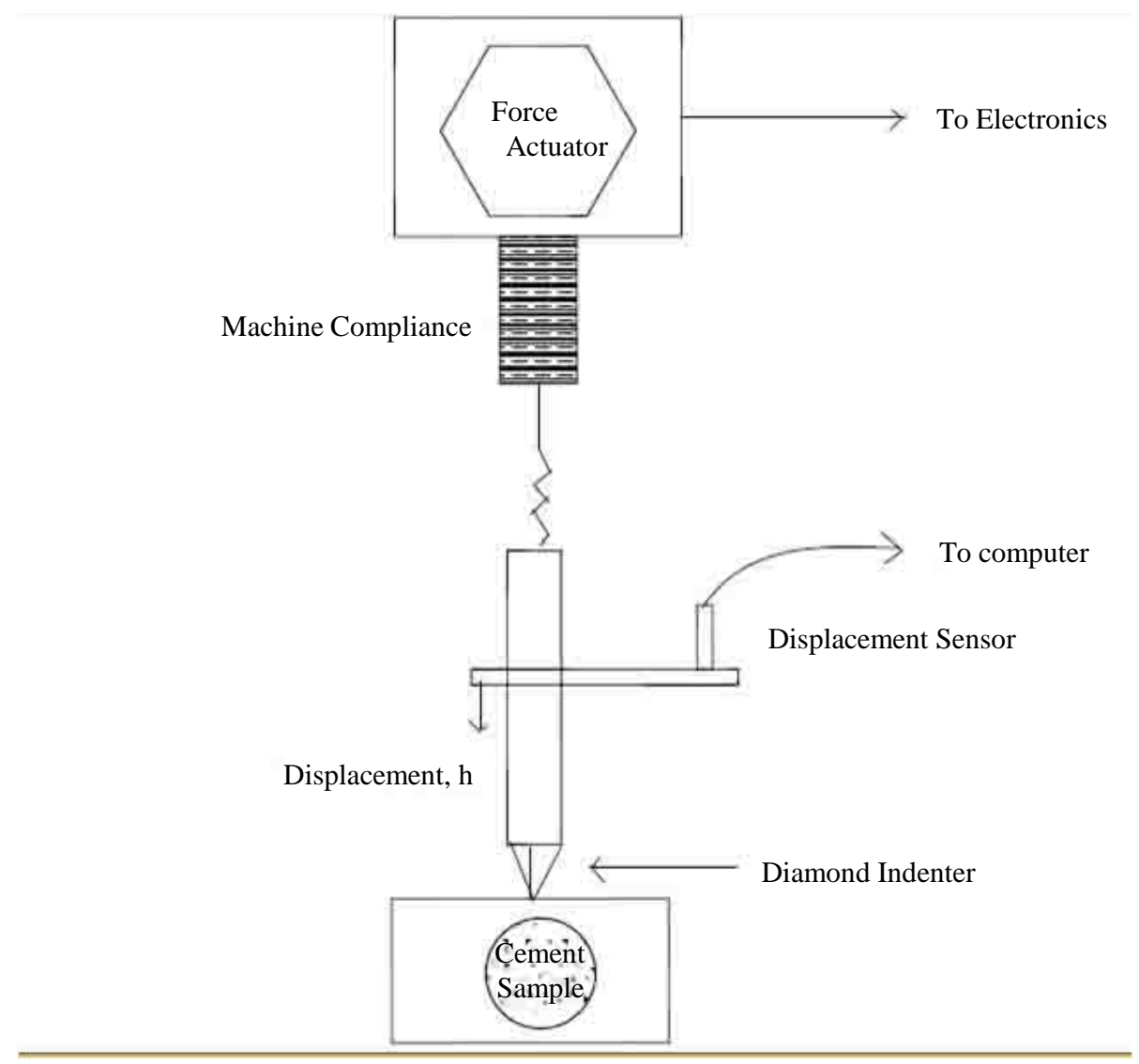

Figure 3. Schematic of the micro-indenter showing the magnet and coil force actuator assembly and capacitive displacement measurement assembly [17].

released until complete unloading is achieved. The applied load values are plotted against the corresponding position of the indenter [16]. The indenter has the capacity to measure the displacement as low as $0.1 \mathrm{~nm}$ resulting from the applying forces as low as $1 \mathrm{nN}$ [18]. Two main parameters hardness and elastic modulus of the material are determined from micro indentation through load/displacement curves. All calculations of hardness and young modulus are carried out at peak load [17] [18]. The maximum applied force was $20 \mathrm{~N}$ while the loading and unloading rate was maintained at $20 \mathrm{~N} / \mathrm{min}$. The contact load was at $30 \mathrm{mN}$ and the pause rate was set at 30 seconds and 0.3 was used as the Poisson's coefficient for the entire test. Seven spot-indentations using a line profile from one end of the composite sample to the other end (Figure 4) to account for the entire cement profile.

\subsection{Compression Procedure}

The expansion experiment begins by loading the sample to be expanded into the lower sample housing of the $135 \mathrm{KN}$ expandable fixtures via the opening at the top of the expansion fixture using either a belt support by two personnel or an engine jack. An expansion mandrel is then extended through the inner pipe of the sample to reach the other end of the sample. The desired expansion ratio cone, which has been lubricated effectively, is placed on the top of the extended expansion mandrel. A lower connector and a retaining mandrel are then screwed onto the lower end of the lower housing unit of the expansion fixture. The axial force recording device is connected from the expansion fixture to the computer via the National Instrument Data Acquisition unit and the force recoding software is activated for measurement. The retract knob on the control switch is activated and this in turn sends signal to the hydraulic unit from the hydraulic pump, which pulls the cone through the inner pipe of the composite sample thereby expanding the diameter of the inner pipe. The expanded pipe in turn compresses the cement sheath behind it leading to the compression of the cement. The samples were compacted over an extended length of $46 \mathrm{~cm}$. 


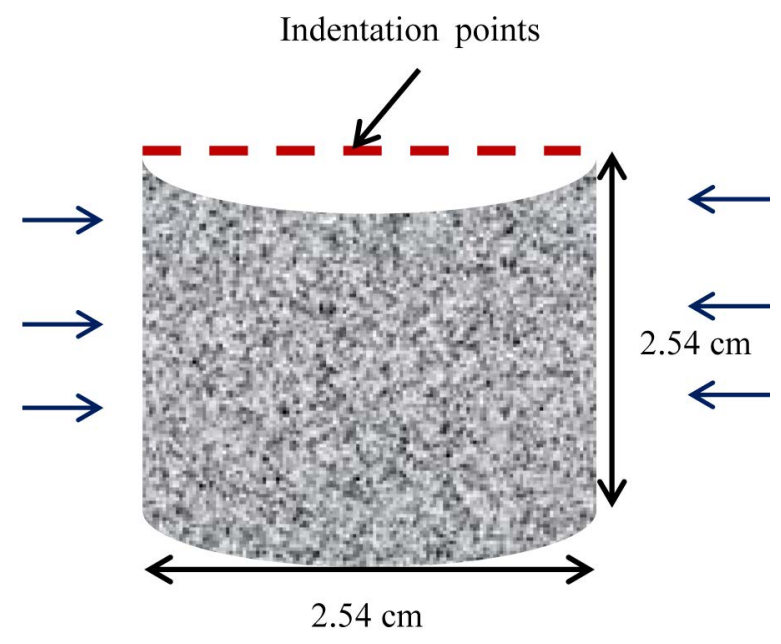

Figure 4. Schematic of the indentation points on the cement core showing the direction of the compression (blue arrows) and the indentation points (red dashed line).

\section{Results}

\subsection{Impact of Compression on Cement Sheath}

The compression and densification of the cement sheath behind the pipe resulted from the impact of the compression forces on the inner pipe of the composite sample (Figure 5). Compression of the cement resulted in changes in the physical structure of the hydrated cement such as pore collapse resulting from the impact of pipe expansion on the cement. This compression results in the release of free pore water contained within the pores of the cement matrix. Most of the changes occurred at the microstructural level and as such the impact of the compression of the length of the cement cores was not significant. The expanded cement composite samples were cut immediately after the expansion experiment to evaluate the impact of the casing expansion on the cement sheath. The compressed cement sheath maintained its consistency with few observable fractures at the top section of the composite sample. These fractures however, were healed after two weeks of rehydration.

\subsection{Alteration in Cement Mineralogical Composition Due to Compression}

The XRD analysis (Figure 6) performed on the crushed cement samples that were finely ground into powders, reflected considerable changes in the mineral composition of the cement after expansion as shown in the altered mineral peaks and reduction in noise level in the X-ray diffractogram. There was an observable increase in portlandite peaks for the expanded samples confirming the creation of minerals which aid in strength development of the cement. The XRD can only detect crystalline phases (CH and un-hydrated cement) and not C-S-H. Also, $\mathrm{XRD}$ can only detect changes greater than $2 \%$ by weight and as such changes occurring during the hydration could not be detected by this technique.

\subsection{Impact of Compression on Cement's Porosity and Permeability}

The porosity of the $1 \times 5.08 \mathrm{~cm}$. cement cores drilled from the cement sheath for the control and the expanded samples were measured using the Helium Intrusion Porosimetry technique and the results are summarized in Table 1. Three sets of cores were drilled from the unexpanded sample and the samples expanded with the three different expansion ratios ( $2 \%, 4 \%$ and $8 \%)$. The porosity of each core was measured three times and averaged as presented. The results confirm a general improvement (reduction) in porosity after expansion. In addition, clogging of the pore throats resulting in reduction in pore throat size accounts for the reduction in porosity post expansion as was seen in a previous study conducted with non-salted cement sample [12].

The permeability results obtained using liquid (water) pressure pulse decay permeameter are summarized in Table 2. Three sets of cores were drilled from the unexpanded sample and the samples expanded with the three different expansion ratios ( $2 \%, 4 \%$ and $8 \%$ ). The permeability of each core was measured three times and averaged 

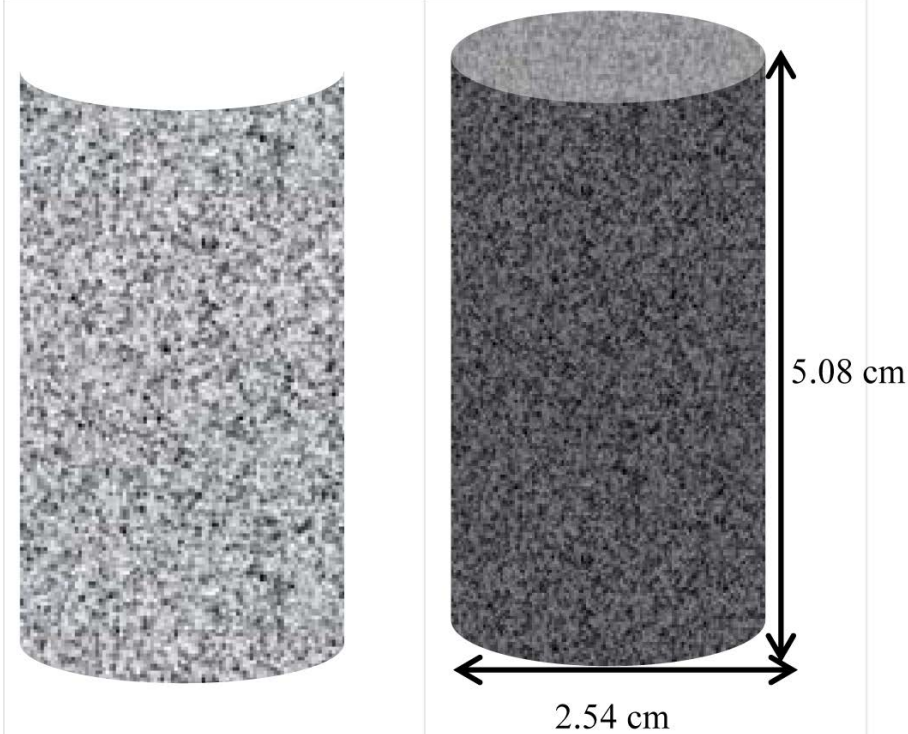

Figure 5. Schematic of the core samples drilled from the cement sheath pre and post compression. (a) Depicts the structure of the cement sheath with entrained air bubbles and large pores before expansion and (b) Depicts smaller pores and densified cement sheath resulting from the compression of the cement sheath after expansion.

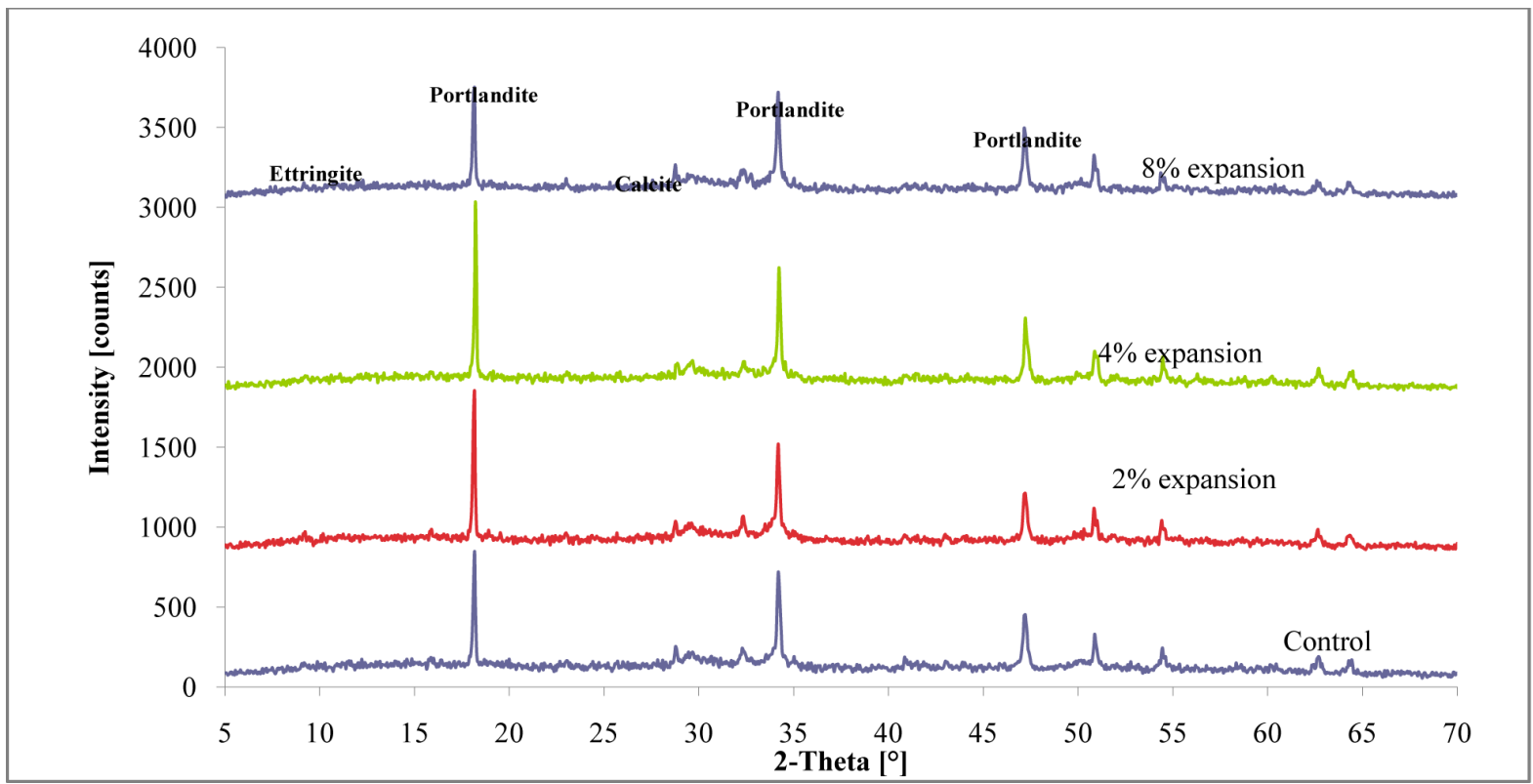

Figure 6. Semi-quantitative X-ray diffractogram plots for the salt cement sample two months' post expansion. The results show major differences in peaks of portlandite and ettringite mineral between the control and the expanded samples.

Table 1. Pre and post compression porosity measurements showing the reduction in porosity post compression.

\begin{tabular}{ccc}
\hline & \multicolumn{2}{c}{ Porosity of cement cores } \\
\hline Expansion ratio (\%) & Pre-compression porosity (\%) & Post-expansion porosity (\%) \\
\hline 2 & & $30.16 \pm 0.1$ \\
4 & $31.02 \pm 0.3$ & $29.87 \pm 0.1$ \\
8 & & $30.12 \pm 0.1$ \\
\hline
\end{tabular}


Table 2. Pre and post compression permeability measurements showing the reduction in permeability post compression.

\begin{tabular}{ccc}
\hline & Permeability of cement cores & \\
\hline Expansion ratio (\%) & Pre-compression permeability (\%) & Post-expansion permeability (\%) \\
\hline 2 & $28.58 \pm 14.5$ & $13.57 \pm 11.9$ \\
4 & & $13.30 \pm 4.45$ \\
8 & $133.13 \pm 17.39$ \\
\hline
\end{tabular}

as presented. A reduction in permeability was observed post expansion, confirming the closure of pore spaces, hence the improvement in zonal isolation. However, the cores drilled from the samples expanded with the 8\% expansion cone have higher permeability when compared to the control sample. This anomaly is attributed to the presence of fractures within the cement cores due to impact. In general, the clogging of the pores as a result of the compression and the precipitation of minerals mainly ettringite aided the reduction of the flow paths for hydraulic conductivity within the cement sheath.

\subsection{Impact of Compression on Cement's Hardness and Young's Modulus}

The hardness of the cement sample pre and post expansion was investigated using the micro-indentation technique (Figure 7). Micro-hardness tests were performed on the drilled cores from the sheath between the inner and the outer pipe of the composite assembly for compacted and non-compacted samples. A minimum of seven indentation points were tested for each of the samples to obtain an average hardness. The hardness tests were performed on the cement samples one month after expansion and the results show that the hardness of the cement increased slightly as a result of the compression of the cement sheath resulting from the pipe expansion. The highest increase in hardness post compression was observed for the sample expanded with the $2 \%$ expansion ratio cone where the increase in hardness of $12 \%$ compared to the control sample was recorded. It has also been shown that the hardness of cement grains increases with hydration period and this can be correlated with hardness of cement [17]. The 4\% expanded samples recorded an increase in Young's modulus whereas the 2\% and the 8\% expanded samples had reduction in Young's modulus. Our findings indicate that although pore collapse had a direct impact of hardness, it has no effect on Young's modulus.

\section{Discussions}

Compression of the cement produced changes in the structure of the hydrated cement, such as pore collapse resulting in the release of free pore water contained within the pores of the cement matrix. This phenomenon has also been observed in a previous study regarding the use of expandable tubular as a remediation method for leaky wells as documented in the literature [15]. The ingress water from the pores also aids in the autogenous healing of cracks and fractures within the cement by triggering hydration of un-hydrated cement particles. Precipitation of new minerals most ettringite was observed after compression and these new minerals are formed due to the triggered reactions between the un-hydrated cement grains and the released pore water. An increase in the hardness of the cement grains after compression was also observed. This further confirms that the compression of the cement is beneficial for the cement both in terms of providing zonal isolation and providing support for the casing. It is important to mention that all of these analyses were performed without confinement and in most situations, oil and gas cement are always under confinement and this is the subject of an ongoing investigation.

\section{Conclusions}

Based on the findings from this study, the following conclusions can be drawn:

1) The reduction in the porosity and permeability of the cement sheath after compression shows that the compression positively impacts the cements ability to prevent flow and provide adequate zonal isolation.

2) The clogging of the pore throats and pores within the cement matrix is the major factor contributing to the improvement in both the mechanical and petro physical properties of the cement upon compression.

3) The compression of the cement is beneficial in the long run as shown from the results obtained. The increase in hardness of the cement aids in proving more support for the casing and it also increases the ability of 


\section{Plot of Hardness and Youngs modulus Vs. Expansion Ratio}

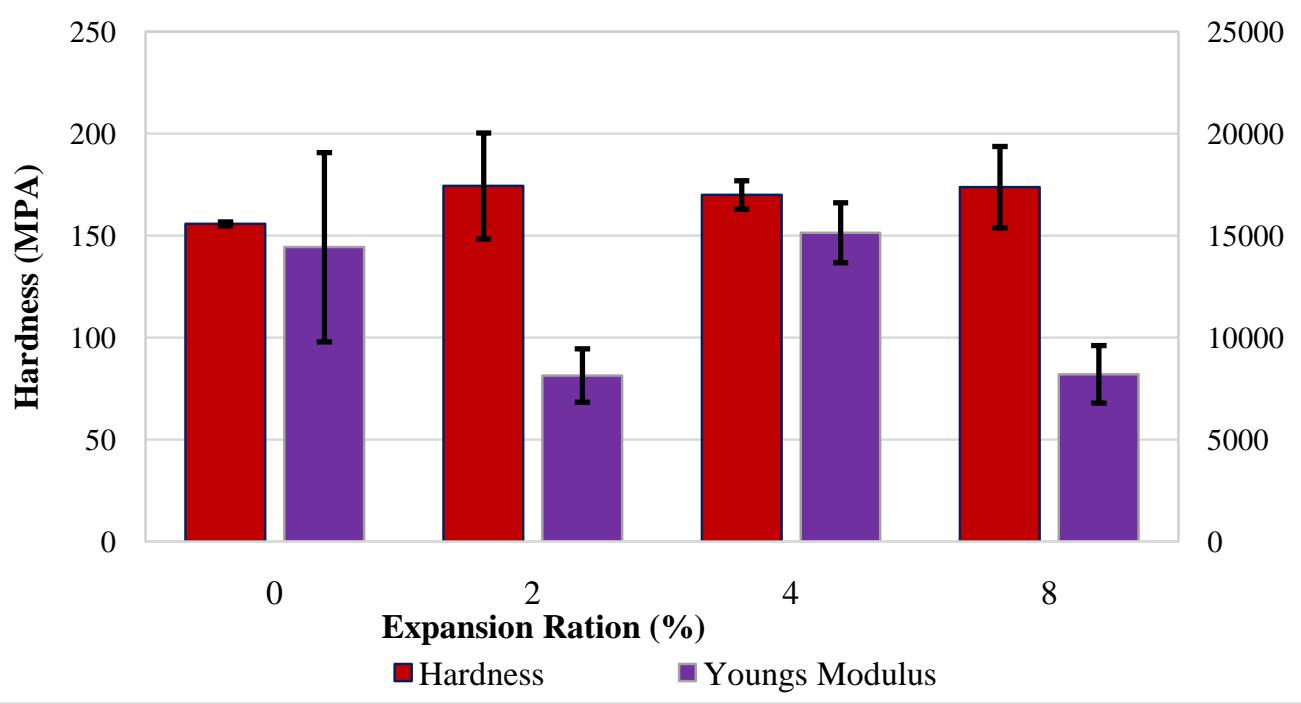

Figure 7. Average cement sample hardness and Young's modulus measured using the micro indentation technique showing the variation of hardness with expansion ratio.

the cement sheath to provide longer term for zonal isolation.

4) The findings from to this study are relevant in the functionality of oil well cementing in field applications. The results demonstrate the positive impact of compression on salted cement systems under similar conditions in field applications. It also shows that the properties of wellbore cements can be improved to achieve adequate zonal isolation.

5) The impact of fracture network on cement sheath and the impact of salt on geochemical changes of cement under compression are under investigation.

\section{Recommendations}

Experiments are currently being performed using more applicable oil well cement designs to quantify the impact of compression on the microstructure, strength and overall performance of salt cement systems. Furthermore, new wellbore models that enable full CT scans of the sample pre and post expansion to visualize the impact of the compression and the fracture network (if any) within the cement matrix, are being designed for future studies.

\section{Acknowledgements}

We thank Shell E \& P for funding this project and the Petroleum engineering department of Louisiana State University for supporting this research. Also, the authors wish to acknowledge the contributions of Richard Dubois (Halliburton), Gerry Masterman and Chris Carver (LSU PERTT lab) and all the members of SEER lab.

\section{References}

[1] Nelson, E.B., Ed. (1990) Well Cementing. Elsevier Science, New York.

[2] Davies, R.J., et al. (2014) Oil and Gas Wells and Their Integrity: Implications for Shale and Unconventional Resource Exploitation. Marine and Petroleum Geology, 56, 239-254. http://dx.doi.org/10.1016/j.marpetgeo.2014.03.001

[3] Jandhyala, S.R.K., Ravi, K. and Anjos, J. (2015) Design Procedure for Cementing Intercalated Salt Zones. OTC Brasil, Rio de Janeiro, Brazil, 27-29 October, 1-3. http://dx.doi.org/10.4043/26310-ms

[4] Lewis, W.J. and Rang, C.L. (1987) Salt Cements for Improved Hydraulic Isolation and Reduce Gas Channeling. SPE California Regional Meeting, Ventura, California, 8-10 April 1987, 1-4. http://dx.doi.org/10.2118/16386-ms

[5] Mbadike, E.M. and Elinwa, A.U. (2012) Effect of Salt Water in the Production of Concrete. Nigerian Journal of 
Technology, 30, 105-110.

[6] Smith, D.K. (1976) Cementing. SPE of AIME Monograph, Vol. 4, Henry L. Doherty Series, Society of Petroleum Engineers, Dallas.

[7] Barlet-Gouédard, V., et al. (2009) A Solution against Well Cement Degradation under $\mathrm{CO}_{2}$ Geological Storage Environment. International Journal of Greenhouse Gas Control, 3, 206-216. http://dx.doi.org/10.1016/j.ijggc.2008.07.005

[8] Griffin, D.F. and Henry, R.L. (1962) The Effect of Salt in Concrete on Compressive Strength, Water Vapor Transmission, and Corrosion of Reinforcing Steel Y-R007-05-01-012.

[9] Longson, W.B. (1964) The Use of Salt Cement Blends as an Aid to Better Cementing in Formations Containing Fresh Water Sensitive Clays. Journal of Canadian Petroleum Technology, 3, 95-100. http://dx.doi.org/10.2118/64-03-02

[10] Glinicki, M.A. and Zielinski, M. (2004) Depth-Sensing Indentation Method for Evaluation of Efficiency of Secondary Cementitious Materials. Cement and Concrete Research, 34, 721-724. http://dx.doi.org/10.1016/j.cemconres.2003.10.014

[11] Kupresan, D., Heathman, J. and Radonjic, M. (2013) Application of a New Physical Model of Expandable Casing Technology in Mitigation of Wellbore Leaks. Journal of Canadian Energy Technology \& Innovation (CETI), 1, No. 5.

[12] Radonjic, M. and Kupresan, D. (2013) Mechanical Expansion of Steel Tubing as a Solution to Leaky Wellbores. Journal of Visualized Experiments, 93, e52098-e52098.

[13] Oliver, W.C. and Pharr, G.M. (2004) Measurement of Hardness and Elastic Modulus by Instrumented Indentation: Advances in Understanding and Refinements to Methodology. Journal of Materials Research, 19, 3-20. http://dx.doi.org/10.1557/jmr.2004.19.1.3

[14] Oyibo, A. and Radonjic, M. (2015) Impact of Compression on the Petro-Physical and Mechanical Properties of Wellbore Cement Containing Salt. 49th US Rock Mechanics/Geomechanics Symposium, San Francisco, CA, USA, 28 June-1 July 2015, 1-7.

[15] API Recommended Practice 90 (2006) Annular Casing Pressure Management for Offshore Wells. American Petroleum Institute, USA.

[16] Radonjic, M. and Oyibo, A. (2014) Comparative Experimental Evaluation of Drilling Fluid Contamination on Shear Bond Strength at Wellbore Cement Interfaces. World Journal of Engineering, 11, 597-604. http://dx.doi.org/10.1260/1708-5284.11.6.597

[17] Hay, J.L. and Pharr, G.M. (2000) Instrumented Indentation Testing. ASM International, Materials Park, OH, $232-243$.

[18] Kumar, V., Sondergeld, C.H. and Rai, C.S. (2012) Nano to Macro Mechanical Characterization of Shale. SPE Annual Technical Conference and Exhibition, San Antonio, TX, USA, 8-10 October 2012, 1-23.

\section{Submit or recommend next manuscript to SCIRP and we will provide best service for you:}

Accepting pre-submission inquiries through Email, Facebook, Linkedin, Twitter, etc

A wide selection of journals (inclusive of 9 subjects, more than 200 journals)

Providing a 24-hour high-quality service

User-friendly online submission system

Fair and swift peer-review system

Efficient typesetting and proofreading procedure

Display of the result of downloads and visits, as well as the number of cited articles

Maximum dissemination of your research work

Submit your manuscript at: http://papersubmission.scirp.org/ 